\title{
Atributos físicos, químicos e biológicos de solo sob produção orgânica impactados por sistemas de cultivo
}

\author{
Eurâimi de Q. Cunha ${ }^{1}$, Luís F. Stone ${ }^{2}$, Enderson P. de B. Ferreira ${ }^{2}$, \\ Agostinho D. Didonet ${ }^{2} \&$ José A. A. Moreira ${ }^{3}$
}

\begin{abstract}
RESU M O
Este trabalho objetivou determinar quais atributos de um Latossolo Vermelho de Cerrado sob produção orgânica são mais impactados por sistemas de cultivo compostos por feijão e milho, semeadura direta (SD) e preparo convencional (PC) do solo e plantas de cobertura. Aplicaram-se técnicas de análise multivariada nos dados de quatro experimentos, dois em SD e dois em PC, um com feijão e outro com milho em cada preparo, instalados desde novembro de 2003, em Santo Antônio de Goiás, GO, no delineamento de blocos ao acaso, com quatro repetições. Em setembro de 2003 foram retiradas amostras de solo na camada de $0-0,10 \mathrm{~m}$ para análise química inicial (referência química). Em novembro de 2007 foi feita nova amostragem nas parcelas e em uma mata próxima (referência física e biológica) para determinação dos atributos físicos (AF), químicos (AQ) e biológicos ( $A B$ ) do solo. Os sistemas de cultivo provocaram alterações nos $A F$ e $A B$, quando comparados com a mata, e nos $A Q$, quando comparados com a condição inicial, sendo os AF mais sensíveis em detectar mudanças na qualidade do solo sob cultivo. Os quocientes metabólico e microbiano foram os mais afetados negativamente pelo PC quando comparados com a SD. O s AQ foram mais sensíveis em discriminar a cultura do feijão da do milho.
\end{abstract}

Palavras-chave: Phaseolus vulgaris L., Zea mays, semeadura direta, preparo do solo, qualidade do solo

\section{Physical, chemical and biological attributes of soil under organic production as impacted by crop systems}

\begin{abstract}
This study aimed to determine which attributes of a Cerrado 0 xisol under organic production are more impacted by cropping systems consisted of combinations of common bean and corn crops, no-tillage (NT) and conventional tillage (CT) systems, and cover crops. Multivariate analysis techniques were applied on data of four experiments, two of them under NT and the other two in CT, one carried out with common bean crop and another with corn. The experiments were installed annually since N ovember 2003 in Santo Antônio de Goiás, G O, in randomized block design, with four replications. Samples were taken from soil layer of 0-0.10 $\mathrm{m}$ in September 2003 for the initial chemical analysis (chemical reference). In N ovember 2007 a new sampling of the plots and of a forest (physical and biological reference) was performed for determination of soil physical (PA), chemical (CA) and biological (BA) attributes. The cropping systems caused changes in PA and BA, as compared to the forest, and in CA, as compared to the initial chemical condition of soil. PA were more sensitive to detect changes in the quality of the soil under cultivation. The metabolic and microbial quotients were the most negatively affected by CT as compared to NT. CA were more sensitive in discriminating common bean crop from corn crop.
\end{abstract}

Key words: Phaseolus vulgaris L., Zea mays, no-tillage, soil tillage, soil quality

D outorando do Curso de Pós-Graduação em Agronomia da UFG, Goiânia, GO. Fone: (62) 3534-9801. E-mail: euraimi@yahoo.com.br Embrapa Arroz e Feijão, CP 179, CEP 75375-000, Santo Antônio de Goiás, GO. Fone: (62) 3533-2151. E-mail: stone@cnpaf.embrapa.br: enderson@cnpaf.embrap.br; didonet@cnpaf.embrapa.br

${ }^{3}$ Embrapa Milho e Sorgo, CP 151, CEP 35701-970, Sete Lagoas, MG. Fone: (31) 3027-1100. E-mail: jaloisio@cnpms.embrapa.br 


\section{INTRODUÇÃO}

A capacidade de um solo específico em desempenhar funções dentro dos limites de ecossistemas naturais ou manejados para sustentar a produtividade das plantas e dos animais, manter ou melhorar a qualidade da água e do ar e dar suporte à saúde e habitação humanas, é definida como qualidade do solo (SSSA, 1995).

Usualmente, a qualidade do solo agrícola é considerada sob três aspectos: físico, químico e biológico, sendo importantes nas avaliações da extensão da degradação ou melhoria do solo e para identificar a sustentabilidade dos sistemas de manejo (Aratani et al., 2009). Segundo alguns autores, a qualidade física do solo merece destaque especial uma vez que tem afetado bastante a qualidade química e biológica, já que uma depende da outra, ou seja, melhorando a qualidade física de determinado solo se está contribuindo indiretamente para a melhoria das suas condições biológicas e químicas (Dexter, 2004; Araújo et al., 2007). Vezzani \& Mielniczuk (2009), contudo, ponderam que as reflexões em relação à qualidade do solo parecem conduzir a indicadores biológicos. As recomendações de manejo direcionam para práticas que favoreçam a biologia do solo, pois os organismos são os responsáveis pelas grandes transformações físicas e químicas no solo, que o habilitam a exercer suas funções na natureza.

Uma das formas de melhorar a qualidade do solo é a adoção de práticas de cultivo orgânico, as quais evitam ou praticamente excluem o uso de fertilizantes e pesticidas sintéticos, procurando substituir insumos adquiridos externamente por aqueles encontrados na propriedade ou próximos (Altieri, 2002). De acordo com Vezzani \& Mielniczuk (2009), os sistemas agrícolas que favorecem a qualidade do solo são aqueles que cultivam plantas intensamente, de preferência de espécies diferentes, sem o revolvimento do solo.

São conhecidos, hoje, efeitos isolados de diferentes preparos e plantas de cobertura nos atributos físicos, químicos e biológicos do solo. Entretanto, no solo existem diversas interrelações entre esses atributos que controlam os processos e os aspectos relacionados à sua variação no tempo e no espaço, de maneira que qualquer alteração no solo pode alterar diretamente sua estrutura e atividade biológica e, em consequência, a fertilidade, com reflexos na sua qualidade e na produtividade das culturas (Carneiro et al., 2009). Diante disso, a avaliação conjunta desses atributos é importante para o melhor manejo do solo e das culturas, visando à sustentabilidade dos sistemas agrícolas.

Tal avaliação é complexa e deve ser realizada em função de um conjunto de indicadores específicos e suas inter-relações, já que se tem verificado que indicadores isolados não são suficientes para explicar a perda ou o ganho potencial dos cultivos de determinado solo. Assim, a utilização de análise multivariada dos dados poderá indicar diferenças e estabelecer as relações entre os tratamentos e os atributos avaliados, tornando-se uma ferramenta importante na análise das informações obtidas (Cruz-Castilho et al., 1994).

Este trabalho objetivou determinar, com o uso de técnicas de análise multivariada, que atributos de um Latossolo Vermelho distrófico de Cerrado sob produção orgânica são mais impactados por diferentes sistemas de cultivo compostos pela combinação das culturas de feijão e milho, da semeadura direta e preparo convencional do solo e também de plantas de cobertura.

\section{Material E MÉTODOS}

O trabalho foi conduzido na Fazenda Capivara, da Embrapa Arroz e Feijão, localizada no município de Santo Antônio de Goiás, GO, compreendida entre as coordenadas $16^{\circ} 31^{\prime} 18^{\prime \prime} \mathrm{S}$, $49^{\circ} 18^{\prime} 45^{\prime \prime} \mathrm{W}, 16^{\circ} 31^{\prime} 18^{\prime \prime} \mathrm{S}, 49^{\circ} 16^{\prime} 07^{\prime \prime} \mathrm{W}, 16^{\circ} 29^{\prime} 02^{\prime \prime} \mathrm{S}, 49^{\circ} 16^{\prime}$ $07^{\prime \prime} \mathrm{W}, 16^{\circ} 29^{\prime} 02^{\prime \prime} \mathrm{S}$ e $49^{\circ} 18^{\prime} 45^{\prime \prime} \mathrm{W}$, com altitude média de 823 m. O clima, conforme classificação de Köppen, é Aw, tropical de savana, megatérmico. O regime pluvial é bem definido, com período chuvoso de outubro a abril e seco de maio a setembro, com precipitação média anual de $1460 \mathrm{~mm}$ (Silva et al., 2002). O solo do local é um Latossolo Vermelho distrófico, de textura franco-argilosa, com $410 \mathrm{~g} \mathrm{~kg}^{-1}$ de areia, $270 \mathrm{~g} \mathrm{~kg}^{-1}$ de silte e 320 $\mathrm{g} \mathrm{kg}^{-1}$ de argila, na camada de 0-0,20 m. Antes da implantação dos experimentos foram aplicados, em toda a área e incorporados com grade aradora $1.620 \mathrm{~kg} \mathrm{ha}^{-1}$ de fosfato natural Arad (33\% de $\mathrm{P}_{2} \mathrm{O}_{5}$ ) e $2.000 \mathrm{~kg} \mathrm{ha}^{-1}$ de calcário. A vegetação original da área experimental era do tipo Cerradão e vinha sendo cultivada no sistema convencional de preparo do solo (gradagens aradora e niveladora) com a rotação milho e soja.

Em novembro de 2003 não apenas foram instalados quatro experimentos mas também conduzidos até o momento das amostragens (novembro de 2007) segundo os preceitos da produção orgânica. Dois experimentos foram conduzidos em semeadura direta e nos outros dois foi feito o preparo convencional do solo com grades aradora e niveladora operando até 0,10-0,15 m de profundidade. Em cada sistema de preparo do solo foi conduzido um experimento com a cultura do milho e outro com a do feijão das águas. Em todos os experimentos foram comparadas, no delineamento de blocos ao acaso, com quatro repetições, as culturas de cobertura: crotalária (Crotalaria juncea), guandu (Cajanus cajan (L.) Millsp), mucuna-preta (Mucuna aterrima), sorgo vassoura (Sorgum technicum) e pousio (vegetação espontânea). A vegetação espontânea era constituída, basicamente, de picão preto (Bidens pilosa), capim pé-de-galinha (Eleusine indica) e leiteiro (Euphorbia heterophylla), com menores ocorrências de braquiária (Brachiaria decumbens), corda de viola (Ipomoea grandifolia), caruru (Amaranthus deflexus), erva de Santa Luzia (Chamaisice viridis L.), trapoeraba (Commelina benghalensis), mentrasto (Ageratum conyzoides), beldroega (Portulaca oleracea), guanxuma (Sida cordifolia) e maria pretinha (Solanum americanum Mill).

As culturas de cobertura foram semeadas em abril de cada ano e conduzidas no sistema de semeadura direta. Por ocasião da semeadura do milho e feijão, em novembro, foram manejadas com rolo-faca e deixadas sobre o solo (semeadura direta) ou incorporadas (preparo convencional). Elas foram semeadas sem adubação no espaçamento de 0,45 m entre linhas, utilizandose 60 sementes por metro de crotalária, guandu e sorgo e 20 sementes por metro de mucuna. O feijoeiro (Phaseolus vulgaris L.) cv. Pérola foi semeado no mesmo espaçamento, com 16 
sementes por metro e o milho (Zea mays L.) cv. AG 1051 no espaçamento de $0,90 \mathrm{~m}$, com 5 sementes por metro, também sem adubação. A área das parcelas com feijão foi de 27,00 m² $(2,70 \times 10,0 \mathrm{~m})$ e as de milho de $54 \mathrm{~m}^{2}(5,40 \times 10,0 \mathrm{~m})$.

Em setembro de 2003, após o revolvimento do solo para incorporar os restos culturais, no caso do preparo convencional mas antes da semeadura do feijoeiro e do milho, foi realizada amostragem inicial do solo para análise química na camada de 0-0,10 m, a qual foi utilizada como referência para os atributos químicos. Em novembro de 2007 foi realizada nova amostragem de solo para análises física, química e biológica, na mesma camada. Foi amostrado, também, o solo de uma mata próxima ao experimento (cerradão), representativa da vegetação original, que foi utilizada como referência para os atributos físicos e biológicos.

Os atributos físicos avaliados foram densidade do solo, determinada pelo método do anel volumétrico, porosidade total, pela relação entre a densidade do solo e a densidade de partículas determinada pelo método do balão volumétrico, microporosidade, considerada igual à quantidade de água retida pelo solo na tensão de $6 \mathrm{kPa}$, macroporosidade, pela diferença entre porosidade total e microporosidade, diâmetro médio ponderado dos agregados, determinado via úmida, porcentagem de agregados com diâmetro maior que $2 \mathrm{~mm}$, sendo as análises realizadas segundo EMBRAPA (1997), índice S, que é a declividade da curva característica de retenção da água do solo em seu ponto de inflexão (Dexter, 2004), e resistência do solo à penetração, determinada com penetrômetro de impacto (Stolf et al., 1983). Os atributos químicos avaliados foram o teor matéria orgânica, determinado pelo método de Walkley \& Black, o pH do solo e os teores de $\mathrm{P}, \mathrm{K}^{+}, \mathrm{Ca}^{2+}, \mathrm{Mg}^{2+}, \mathrm{Cu}^{2+}, \mathrm{Zn}^{2+}$, $\mathrm{Fe}^{3+}, \mathrm{Mn}^{2+}, \mathrm{H}^{+}+\mathrm{Al}^{3+}$, além de calculadas a capacidade de troca de cátions a pH 7 (CTC) e a saturação por bases (V). O pH foi determinado em água. $\mathrm{O}$ fósforo e o potássio foram extraídos com a solução de Mehlich $1\left(\mathrm{HCl}\right.$ a $0,5 \mathrm{~N}+\mathrm{H}_{2} \mathrm{SO}_{4}$ a $\left.0,025 \mathrm{~N}\right)$ e determinados em colorímetro e fotômetro de chama, respectivamente. $\mathrm{O} \mathrm{Ca}^{2+}$ e o $\mathrm{Mg}^{2+}$ foram extraídos em $\mathrm{KCl}$ a $1 \mathrm{~N}$ e determinados por titulação de EDTA. Os micronutrientes foram determinados em espectrofotômetro de absorção atômica utilizando-se o extrator Mehlich $1 . \mathrm{OH}^{+}+\mathrm{Al}^{3+}$ foi determinado por titulometria, usando-se solução de acetato de cálcio $1 \mathrm{~N} \mathrm{a}$ pH 7 para sua extração. As análises laboratoriais foram realizadas de acordo com EMBRAPA (1997). Os atributos biológicos avaliados foram carbono orgânico total do solo (EMBRAPA, 1997), carbono (CBM) da biomassa microbiana, determinado pelo método da fumigação-extração proposto por Vance et al. (1987), respiração basal do solo (RBS), determinada pela quantificação do $\mathrm{CO}_{2}$ liberado durante a incubação do solo em sistema fechado (Jenkinson \& Powlson, 1976), e quocientes metabólico $\left(\mathrm{qCO}_{2}\right)$, obtido pela relação entre RBS e CBM, e microbiano (qmic), obtido pela relação entre CBM e COT (Anderson \& Domsch, 1993).

Para cada atributo estudado calcularam-se a média e o desvio-padrão, pela estatística clássica. Foi utilizada a técnica multivariada por meio da análise de componentes principais, envolvendo todos os experimentos e atributos em estudo, a partir da qual foi reduzido o conjunto de dados em combinações (COT), determinado pelo método de Walkley \& Black

lineares, gerando escores dos componentes principais que explicam em torno de $80 \%$ da variação total, conforme recomendado por Cruz \& Regazzi (1994). Isto permitiu identificar os atributos mais relevantes na discriminação dos diferentes tratamentos. Adicionalmente, efetuou-se a análise de agrupamento pelo método de Ward. Amedida de dissimilaridade utilizada foi a distância euclidiana média. As análises multivariadas foram feitas com o auxílio do Programa R (R Development Core Team, 2011).

\section{RESULTADOS E DISCUSSÃO}

A análise de componentes principais mostrou que a variância acumulada nos primeiros três componentes foi de $83,5 \%$, tendo o primeiro explicado $52,9 \%$ da variância total, o segundo $16,6 \%$ e o terceiro $14,0 \%$.

Os atributos do solo que propiciaram os maiores índices de correlação com o primeiro componente principal $(r>0,60)$ foram todos os atributos físicos, os teores de matéria orgânica, cálcio, fósforo, potássio, ferro e manganês entre os atributos químicos, e o carbono orgânico total, o carbono da biomassa microbiana e a respiração basal do solo entre os atributos biológicos (Tabela 1). Esses atributos foram responsáveis por discriminar os sistemas de cultivo em relação à referência.

Os atributos físicos foram os mais impactados negativamente com o uso do solo sob vegetação de Cerrado para a produção agrícola. Araújo et al. (2007) também verificaram,

Tabela 1. Correlação entre cada componente principal e os atributos físicos, químicos e biológicos da camada de 0-0,10 m do Latossolo Vermelho distrófico cultivado com feijão e milho e submetido a diferentes preparose plantas de cobertura

\begin{tabular}{|c|c|c|c|}
\hline Atributos & CP1 & CP2 & CP3 \\
\hline Densidade do solo $\left(\mathrm{Mg} \mathrm{m}^{-3}\right)$ & 0,988 & 0,109 & $-0,020$ \\
\hline Porosidade total $\left(\mathrm{m}^{3} \mathrm{~m}^{-3}\right)$ & $-0,989$ & $-0,108$ & 0,020 \\
\hline Microporosidade $\left(\mathrm{m}^{3} \mathrm{~m}^{-3}\right)$ & 0,935 & $-0,044$ & $-0,177$ \\
\hline Macroporosidade $\left(\mathrm{m}^{3} \mathrm{~m}^{-3}\right)$ & $-0,989$ & $-0,071$ & 0,059 \\
\hline Agregados com diâmetro > 2 mm (\%) & $-0,868$ & 0,286 & 0,214 \\
\hline Diâmetro médio ponderado dos agregados $(\mathrm{mm})$ & $-0,952$ & 0,154 & 0,050 \\
\hline Resistência do solo à penetração (MPa) & 0,666 & 0,595 & $-0,210$ \\
\hline Índice $S^{*}$ & $-0,993$ & $-0,059$ & $-0,064$ \\
\hline Teor de matéria orgânica do solo $\left(\mathrm{g} \mathrm{dm}^{-3}\right)$ & 0,691 & $-0,267$ & 0,574 \\
\hline pH em água & $-0,297$ & $-0,376$ & 0,742 \\
\hline Teor de cálcio trocável $\left(\mathrm{cmol}_{\mathrm{c}} \mathrm{dm}^{-3}\right)$ & $-0,735$ & 0,171 & $-0,059$ \\
\hline Teor de magnésio trocável $\left(\mathrm{cmol}_{\mathrm{c}} \mathrm{dm}^{-3}\right)$ & $-0,326$ & 0,421 & 0,258 \\
\hline Teor de fósforo disponível $\left(\mathrm{mg} \mathrm{dm}^{-3}\right)$ & $-0,717$ & 0,402 & 0,353 \\
\hline Teor de potássio disponível $\left(\mathrm{mg} \mathrm{dm}^{-3}\right)$ & $-0,920$ & $-0,182$ & $-0,165$ \\
\hline Teor de cobre disponivel $\left(\mathrm{mg} \mathrm{dm}^{-3}\right)$ & $-0,001$ & $-0,917$ & $-0,065$ \\
\hline Teor de zinco disponível ( $\mathrm{mg} \mathrm{dm}^{-3}$ ) & $-0,053$ & 0,189 & 0,679 \\
\hline Teor de ferro disponível $\left(\mathrm{mg} \mathrm{dm}^{-3}\right)$ & $-0,908$ & $-0,055$ & $-0,095$ \\
\hline Teor de manganês disponível (mg dm ${ }^{-3}$ ) & $-0,850$ & $-0,382$ & 0,165 \\
\hline Capacidade de troca catiônica $\left(\mathrm{c} \mathrm{mol}_{\mathrm{c}} \mathrm{dm}^{-3}\right.$ ) & $-0,488$ & 0,542 & $-0,594$ \\
\hline Saturação por bases (\%) & $-0,030$ & $-0,477$ & 0,806 \\
\hline Carbono orgânico total $\left(\mathrm{g} \mathrm{kg}^{-1}\right)$ & $-0,991$ & $-0,087$ & $-0,027$ \\
\hline Carbono da biomassa microbiana - CBM, $\left(\mathrm{mg} \mathrm{kg}^{-1}\right)$ & $-0,750$ & 0,497 & 0,062 \\
\hline Respiração basal do solo (mg C- $\left.\mathrm{CO}_{2} \mathrm{~kg}^{-1} \mathrm{~h}^{-1}\right)$ & $-0,633$ & $-0,392$ & $-0,574$ \\
\hline Quociente metabólico (mg C-CO $\mathrm{kg}^{-1} \mathrm{CBM} \mathrm{h}^{-1}$ ) & $-0,013$ & $-0,686$ & $-0,651$ \\
\hline Quociente microbiano (\%) & 0,087 & 0,791 & 0,108 \\
\hline
\end{tabular}


comparando a qualidade do solo em área de Cerrado nativo e em áreas sob diferentes usos, que os atributos físicos do solo foram os mais afetados pelos tipos de uso avaliados. As alterações físicas podem influenciar na maioria dos fenômenos importantes que ocorrem no solo, incluindo a quantidade de calor, água e gases transportados, e sua resistência mecânica (Pereira et al., 2010).

Por não sofrer o trânsito de máquinas e equipamentos, o solo sob mata apresentou menores valores de densidade e microporosidade e maiores valores de macroporosidade e porosidade total, em relação ao solo cultivado (Tabela 2), concordando com os resultados de Silva et al. (2008) e Andrade et al. (2009). Verificou-se ainda maior diâmetro médio ponderado dos agregados e porcentagem de agregados com diâmetro maior que $2 \mathrm{~mm}$, o que concorda com os resultados obtidos por Corrêa (2002) e Silva et al. (2008), que constataram maior agregação nos sistemas em equilíbrio com também maiores teores de matéria orgânica e boa diversidade e atividade microbiana na massa do solo.

Em relação ao solo sob mata, a maior densidade do solo cultivado refletiu-se na sua maior resistência à penetração (RP) (Tabela 2). Carneiro et al. (2009) e Cavalcante et al. (2011) também observaram menor RP em solo sob vegetação nativa em relação ao solo cultivado. $\mathrm{O}$ solo sob mata apresentou maior índice $\mathrm{S}$ que o solo cultivado, indicando melhor qualidade física, concordando com os resultados de Silva et al. (2008), Andrade et al. (2009) e Aratani et al. (2009). Este atributo apresentou o maior coeficiente de correlação com o primeiro componente principal, mostrando tratar-se de um indicador adequado da qualidade física do solo, como constataram Andrade et al. (2009).

O cultivo do solo com o uso de plantas de cobertura aumentou o teor de matéria orgânica do solo em relação aos teores iniciais (Tabela 3), concordando com Correia \& Durigan (2008). Os teores de cálcio trocável e de fósforo, potássio, ferro e manganês disponíveis diminuíram, por sua vez, em relação aos teores iniciais.
Como os experimentos não foram adubados infere-se que a reciclagem pelas plantas de cobertura não foi suficiente para compensar a exportação desses nutrientes pelos grãos de feijão e de milho. No caso do fósforo também se deve considerar sua adsorção ao solo e, no caso do ferro, a complexação pela matéria orgânica deve ter exercido papel relevante. A manutenção pelas plantas de cobertura do pH elevado ao longo do tempo também pode ter contribuído para a indisponibilidade desse elemento e do manganês. Alleoni et al. (2005) verificaram correlação negativa entre o $\mathrm{pH}$ e os teores de ferro e de manganês.

O carbono orgânico total sob mata foi maior do que no solo cultivado (Tabela 4) em razão, provavelmente, do grande aporte de resíduos orgânicos, não-revolvimento do solo e reduzida erosão hídrica pela maior cobertura do solo pela liteira, concordando com os resultados de Jakelaitis et al. (2008) e Pôrto et al. (2009). De acordo com Jakelaitis et al. (2008), a diminuição no carbono orgânico total nos solos sob cultivo pode ser devida também ao aumento no consumo do carbono prontamente disponível pela biomassa microbiana e, ainda, pelo manejo adotado.

O teor de carbono da biomassa microbiana no solo sob mata também foi maior do que no solo cultivado (Tabela 4), concordando com os resultados de Porto et al. (2009) e Ferreira et al. (2010). O maior valor de CBM na mata é reflexo de uma situação particular para a microbiota do solo nesse sistema, estimulada pelo fornecimento contínuo de materiais orgânicos com diferentes graus de susceptibilidade à decomposição, originados da vegetação.

A diversidade das espécies vegetais da mata nativa, notadamente maior que dos sistemas agrícolas avaliados, implica em deposição na serapilheira de substratos orgânicos oxidáveis com composição variada. Além disso, existe maior diversidade de compostos orgânicos depositados na rizosfera, o que constitui fator favorável à sobrevivência e crescimento de diferentes grupos de micro-organismos do solo. Neste sentido, a abundância de micro-organismos decompositores

Tabela 2. Média e desvio-padrão dos atributos físicos na camada de 0-0,10 m do Latossolo Vermelho distrófico submetido a diferentes tratamentos

\begin{tabular}{|c|c|c|c|c|c|c|c|}
\hline Atributo & & Referência $^{1}$ & $\begin{array}{l}\text { Sistema } \\
\text { de cultivo }\end{array}$ & $\begin{array}{c}\text { Semeadura } \\
\text { direta }\end{array}$ & $\begin{array}{c}\text { Preparo } \\
\text { convencional }\end{array}$ & Feijão & Milho \\
\hline Densidade do solo $\left(\mathrm{Mg} \mathrm{m}^{-3}\right)$ & $\begin{array}{l}\text { Média } \\
\text { D.P. }{ }^{2}\end{array}$ & $\begin{array}{l}0,890 \\
0,023\end{array}$ & $\begin{array}{l}1,300 \\
0,046\end{array}$ & $\begin{array}{l}1,300 \\
0,038\end{array}$ & $\begin{array}{l}1,300 \\
0,054\end{array}$ & $\begin{array}{l}1,330 \\
0,029\end{array}$ & $\begin{array}{l}1,270 \\
0,033\end{array}$ \\
\hline Porosidade total $\left(\mathrm{m}^{3} \mathrm{~m}^{-3}\right)$ & $\begin{array}{l}\text { Média } \\
\text { D.P. }\end{array}$ & $\begin{array}{l}0,666 \\
0,009\end{array}$ & $\begin{array}{l}0,510 \\
0,017\end{array}$ & $\begin{array}{l}0,509 \\
0,015\end{array}$ & $\begin{array}{l}0,511 \\
0,020\end{array}$ & $\begin{array}{l}0,497 \\
0,011\end{array}$ & $\begin{array}{l}0,523 \\
0,012\end{array}$ \\
\hline Microporosidade $\left(\mathrm{m}^{3} \mathrm{~m}^{-3}\right)$ & $\begin{array}{l}\text { Média } \\
\text { D.P. }\end{array}$ & $\begin{array}{l}0,305 \\
0,006\end{array}$ & $\begin{array}{l}0,353 \\
0,011\end{array}$ & $\begin{array}{l}0,348 \\
0,010\end{array}$ & $\begin{array}{l}0,358 \\
0,010\end{array}$ & $\begin{array}{l}0,358 \\
0,012\end{array}$ & $\begin{array}{l}0,348 \\
0,006\end{array}$ \\
\hline Macroporosidade $\left(\mathrm{m}^{3} \mathrm{~m}^{-3}\right)$ & $\begin{array}{l}\text { Média } \\
\text { D.P. }\end{array}$ & $\begin{array}{l}0,361 \\
0,014\end{array}$ & $\begin{array}{l}0,157 \\
0,025\end{array}$ & $\begin{array}{l}0,161 \\
0,022\end{array}$ & $\begin{array}{l}0,153 \\
0,029\end{array}$ & $\begin{array}{l}0,140 \\
0,022\end{array}$ & $\begin{array}{l}0,174 \\
0,014\end{array}$ \\
\hline Agregados com diâmetro > 2 mm (\%) & $\begin{array}{l}\text { Média } \\
\text { D.P. }\end{array}$ & $\begin{array}{l}94,1 \\
2,889\end{array}$ & $\begin{array}{l}63,2 \\
8,811\end{array}$ & $\begin{array}{l}70,2 \\
3,707\end{array}$ & $\begin{array}{l}56,2 \\
6,338\end{array}$ & $\begin{array}{l}60,9 \\
8,721\end{array}$ & $\begin{array}{l}65,5 \\
8,701\end{array}$ \\
\hline Diâmetro médio ponderado dos agregados (mm) & $\begin{array}{l}\text { Média } \\
\text { D.P. }\end{array}$ & $\begin{array}{l}12,0 \\
0,491\end{array}$ & $\begin{array}{l}6,0 \\
0,983\end{array}$ & $\begin{array}{l}6,6 \\
0,471\end{array}$ & $\begin{array}{l}5,3 \\
0,937\end{array}$ & $\begin{array}{l}5,8 \\
0,916\end{array}$ & $\begin{array}{l}6,2 \\
1,045\end{array}$ \\
\hline Resistência do solo à penetração (MPa) & $\begin{array}{l}\text { Média } \\
\text { D.P. }\end{array}$ & $\begin{array}{l}0,740 \\
0,103\end{array}$ & $\begin{array}{l}1,700 \\
0,521\end{array}$ & $\begin{array}{l}1,970 \\
0,353\end{array}$ & $\begin{array}{l}1,440 \\
0,543\end{array}$ & $\begin{array}{l}2,070 \\
0,303\end{array}$ & $\begin{array}{l}1,340 \\
0,435\end{array}$ \\
\hline Índice S & $\begin{array}{l}\text { Média } \\
\text { D.P. }\end{array}$ & $\begin{array}{l}0,091 \\
0,008\end{array}$ & $\begin{array}{l}0,032 \\
0,004\end{array}$ & $\begin{array}{l}0,031 \\
0,003\end{array}$ & $\begin{array}{l}0,032 \\
0,005\end{array}$ & $\begin{array}{l}0,029 \\
0,003\end{array}$ & $\begin{array}{l}0,034 \\
0,004\end{array}$ \\
\hline
\end{tabular}

${ }^{1}$ Referência - mata nativa; ${ }^{2}$ D.P. - desvio-padrão 
Tabela 3. M édia e desvio-padrão dos atributos químicos na camada de $0-0,10 \mathrm{~m}$ do Latossolo Vermelho distrófico submetido a diferentes tratamentos

\begin{tabular}{|c|c|c|c|c|c|c|c|}
\hline Atributo & & Referência $^{1}$ & $\begin{array}{c}\text { Sistema } \\
\text { de cultivo }\end{array}$ & $\begin{array}{l}\text { Semeadura } \\
\text { direta }\end{array}$ & $\begin{array}{c}\text { Preparo } \\
\text { convencional }\end{array}$ & Feijão & Milho \\
\hline Teor de matéria orgânica do solo $\left(\mathrm{g} \mathrm{dm}^{-3}\right)$ & $\begin{array}{l}\text { Média } \\
\text { D.P. }{ }^{2}\end{array}$ & $\begin{array}{r}20,30 \\
0,50\end{array}$ & $\begin{array}{r}22,00 \\
0,54\end{array}$ & $\begin{array}{r}22,00 \\
0,51\end{array}$ & $\begin{array}{r}22,00 \\
0,60\end{array}$ & $\begin{array}{r}21,50 \\
0,28\end{array}$ & $\begin{array}{r}22,40 \\
0,28\end{array}$ \\
\hline pH em água & $\begin{array}{l}\text { Média } \\
\text { D.P. }\end{array}$ & $\begin{array}{l}6,28 \\
0,10\end{array}$ & $\begin{array}{l}6,23 \\
0,10\end{array}$ & $\begin{array}{l}6,23 \\
0,13\end{array}$ & $\begin{array}{l}6,23 \\
0,08\end{array}$ & $\begin{array}{l}6,15 \\
0,05\end{array}$ & $\begin{array}{l}6,31 \\
0,07\end{array}$ \\
\hline Teor de cálcio trocável $\left(\mathrm{cmol}_{\mathrm{c}} \mathrm{dm}^{-3}\right)$ & $\begin{array}{l}\text { Média } \\
\text { D.P. }\end{array}$ & $\begin{array}{l}3,80 \\
0,22\end{array}$ & $\begin{array}{l}3,50 \\
0,09\end{array}$ & $\begin{array}{l}3,50 \\
0,11\end{array}$ & $\begin{array}{l}3,50 \\
0,08\end{array}$ & $\begin{array}{l}3,50 \\
0,09\end{array}$ & $\begin{array}{l}3,50 \\
0,10\end{array}$ \\
\hline Teor de magnésio trocável $\left(\mathrm{cmol}_{\mathrm{c}} \mathrm{dm}^{-3}\right)$ & $\begin{array}{l}\text { Média } \\
\text { D.P. }\end{array}$ & $\begin{array}{l}1,30 \\
0,13\end{array}$ & $\begin{array}{l}1,20 \\
0,06\end{array}$ & $\begin{array}{l}1,20 \\
0,05\end{array}$ & $\begin{array}{l}1,20 \\
0,05\end{array}$ & $\begin{array}{l}1,20 \\
0,05\end{array}$ & $\begin{array}{l}1,20 \\
0,07\end{array}$ \\
\hline Teor de fósforo disponível (mg dm³) & $\begin{array}{l}\text { Média } \\
\text { D.P. }\end{array}$ & $\begin{array}{r}31,60 \\
6,37\end{array}$ & $\begin{array}{r}15,50 \\
7,62\end{array}$ & $\begin{array}{r}21,50 \\
5,97\end{array}$ & $\begin{array}{l}9,50 \\
2,55\end{array}$ & $\begin{array}{r}14,10 \\
8,35\end{array}$ & $\begin{array}{r}16,90 \\
6,98\end{array}$ \\
\hline Teor de potássio disponível $\left(\mathrm{mg} \mathrm{dm}^{-3}\right)$ & $\begin{array}{l}\text { Média } \\
\text { D.P. }\end{array}$ & $\begin{array}{r}144,00 \\
2,94\end{array}$ & $\begin{array}{r}98,00 \\
7,19\end{array}$ & $\begin{array}{r}94,00 \\
5,17\end{array}$ & $\begin{array}{r}102,00 \\
7,20\end{array}$ & $\begin{array}{r}96,00 \\
8,58\end{array}$ & $\begin{array}{r}100,00 \\
4,86\end{array}$ \\
\hline Teor de cobre disponível $\left(\mathrm{mg} \mathrm{dm}^{-3}\right)$ & $\begin{array}{c}\text { Média } \\
\text { D.P. }\end{array}$ & $\begin{array}{l}2,20 \\
0,22\end{array}$ & $\begin{array}{l}2,20 \\
0,31\end{array}$ & $\begin{array}{l}2,00 \\
0,21\end{array}$ & $\begin{array}{l}2,40 \\
0,20\end{array}$ & $\begin{array}{l}2,10 \\
0,28\end{array}$ & $\begin{array}{l}2,30 \\
0,29\end{array}$ \\
\hline Teor de zinco disponível $\left(\mathrm{mg} \mathrm{dm}^{-3}\right)$ & $\begin{array}{l}\text { Média } \\
\text { D.P. }\end{array}$ & $\begin{array}{l}3,20 \\
0,56\end{array}$ & $\begin{array}{l}3,30 \\
0,46\end{array}$ & $\begin{array}{l}3,50 \\
0,28\end{array}$ & $\begin{array}{l}3,00 \\
0,51\end{array}$ & $\begin{array}{l}3,00 \\
0,53\end{array}$ & $\begin{array}{l}3,50 \\
0,23\end{array}$ \\
\hline Teor de ferro disponível $\left(\mathrm{mg} \mathrm{dm}^{-3}\right)$ & $\begin{array}{l}\text { Média } \\
\text { D.P. }\end{array}$ & $\begin{array}{r}41,00 \\
2,63\end{array}$ & $\begin{array}{r}26,00 \\
3,33\end{array}$ & $\begin{array}{r}25,00 \\
3,23\end{array}$ & $\begin{array}{r}26,00 \\
3,58\end{array}$ & $\begin{array}{r}25,00 \\
3,30\end{array}$ & $\begin{array}{r}26,00 \\
3,52\end{array}$ \\
\hline Teor de manganês disponível ( $\mathrm{mg} \mathrm{dm}^{-3}$ ) & $\begin{array}{l}\text { Média } \\
\text { D.P. }\end{array}$ & $\begin{array}{r}75,00 \\
4,24\end{array}$ & $\begin{array}{r}53,00 \\
6,50\end{array}$ & $\begin{array}{r}51,00 \\
4,41\end{array}$ & $\begin{array}{r}55,00 \\
7,80\end{array}$ & $\begin{array}{r}48,00 \\
1,99\end{array}$ & $\begin{array}{r}58,00 \\
4,77\end{array}$ \\
\hline Capacidade de troca catiônica (mg dm-3) & $\begin{array}{l}\text { Média } \\
\text { D.P. }\end{array}$ & $\begin{array}{l}9,80 \\
0,13\end{array}$ & $\begin{array}{l}8,80 \\
0,61\end{array}$ & $\begin{array}{l}8,90 \\
0,64\end{array}$ & $\begin{array}{l}8,60 \\
0,58\end{array}$ & $\begin{array}{l}9,30 \\
0,36\end{array}$ & $\begin{array}{l}8,30 \\
0,24\end{array}$ \\
\hline Saturação por bases (\%) & $\begin{array}{l}\text { Média } \\
\text { D.P. }\end{array}$ & $\begin{array}{r}55,70 \\
2,60\end{array}$ & $\begin{array}{r}56,60 \\
3,37\end{array}$ & $\begin{array}{r}56,30 \\
3,86\end{array}$ & $\begin{array}{r}56,90 \\
2,99\end{array}$ & $\begin{array}{r}53,70 \\
1,35\end{array}$ & $\begin{array}{r}59,50 \\
1,82\end{array}$ \\
\hline
\end{tabular}

Tabela 4. Média e desvio-padrão dos atributos biológicos na camada de 0-0,10 m do Latossolo Vermelho distrófico submetido a diferentes tratamentos

\begin{tabular}{|c|c|c|c|c|c|c|c|}
\hline Atributo & & Referência $^{1}$ & $\begin{array}{c}\text { Sistema } \\
\text { de cultivo }\end{array}$ & $\begin{array}{c}\text { Semeadura } \\
\text { direta }\end{array}$ & $\begin{array}{c}\text { Preparo } \\
\text { convencional }\end{array}$ & Feijão & Milho \\
\hline Carbono orgânico total $\left(\mathrm{g} \mathrm{kg}^{-1}\right)$ & $\begin{array}{l}\text { Média } \\
\text { D.P. }{ }^{2}\end{array}$ & $\begin{array}{r}17,030 \\
0,429\end{array}$ & $\begin{array}{l}9,850 \\
0,551\end{array}$ & $\begin{array}{l}9,810 \\
0,467\end{array}$ & $\begin{array}{l}9,890 \\
0,648\end{array}$ & $\begin{array}{l}9,380 \\
0,275\end{array}$ & $\begin{array}{c}10,310 \\
0,298\end{array}$ \\
\hline Carbono da biomassa microbiana - CBM, $\left(\mathrm{mg} \mathrm{kg}^{-1}\right)$ & $\begin{array}{l}\text { Média } \\
\text { D.P. }\end{array}$ & $\begin{array}{l}414,6 \\
26,137\end{array}$ & $\begin{array}{l}254,8 \\
61,572\end{array}$ & $\begin{array}{l}289,7 \\
60,527\end{array}$ & $\begin{array}{l}219,8 \\
40,355\end{array}$ & $\begin{array}{l}262,9 \\
78,790\end{array}$ & $\begin{array}{l}246,6 \\
40,582\end{array}$ \\
\hline Res piração basal do solo - RBS, (mg C- $\left.\mathrm{CO}_{2} \mathrm{~kg}^{-1} \mathrm{~h}^{-1}\right)$ & $\begin{array}{l}\text { Média } \\
\text { D.P. }\end{array}$ & $\begin{array}{c}0,88 \\
0,377\end{array}$ & $\begin{array}{l}0,400 \\
0,194\end{array}$ & $\begin{array}{l}0,230 \\
0,066\end{array}$ & $\begin{array}{l}0,570 \\
0,111\end{array}$ & $\begin{array}{l}0,460 \\
0,216\end{array}$ & $\begin{array}{l}0,340 \\
0,156\end{array}$ \\
\hline Quociente metabólico ( $\mathrm{mg} \mathrm{C}-\mathrm{CO}_{2} \mathrm{~kg}^{-1} \mathrm{CBM} \mathrm{h}^{-1}$ ) & $\begin{array}{l}\text { Média } \\
\text { D.P. }\end{array}$ & $\begin{array}{l}2,100 \\
0,793\end{array}$ & $\begin{array}{l}1,790 \\
1,124\end{array}$ & $\begin{array}{l}0,830 \\
0,515\end{array}$ & $\begin{array}{l}2,760 \\
0,573\end{array}$ & $\begin{array}{l}1,980 \\
1,275\end{array}$ & $\begin{array}{l}1,610 \\
0,980\end{array}$ \\
\hline Quociente microbiano (\%) & $\begin{array}{l}\text { Média } \\
\text { D.P. }\end{array}$ & $\begin{array}{l}2,440 \\
0,211\end{array}$ & $\begin{array}{l}2,600 \\
0,669\end{array}$ & $\begin{array}{l}2,960 \\
0,663\end{array}$ & $\begin{array}{l}2,240 \\
0,462\end{array}$ & $\begin{array}{l}2,800 \\
0,818\end{array}$ & $\begin{array}{l}2,390 \\
0,423\end{array}$ \\
\hline
\end{tabular}

${ }^{1}$ Referência - mata nativa; ${ }^{2}$ D.P. - desvio-padrão

pode contribuir para ainda estimular sua microfauna saprófita e predadora. Desta forma, as condições distintas do solo sob vegetação de mata, juntamente com a ausência de perturbações decorrentes de atividade antrópica, tornam possível a existência de maiores quantidades de CBM, indicando o maior equilíbrio da microbiota do solo nesse ecossistema (Pôrto et al., 2009; Ferreira et al., 2010). Nunes et al. (2009) e Ferreira et al. (2010) verificaram, por meio de análise multivariada, que entre os atributos biológicos do solo o CBM foi o que mais contribuiu para a separação da mata de áreas sob diversos usos. Silva et al. (2010) também ressaltaram que o CBM está entre os mais valiosos e sensíveis indicadores da qualidade do solo nos trópicos, como resultado do regime de manejo adotado.
A respiração basal do solo cultivado (RBS) foi menor em comparação com a mata (Tabela 4) concordando com os resultados obtidos por Fialho et al. (2006). A maior liberação de $\mathrm{qCO}_{2}$ geralmente está associada à maior atividade biológica que, por sua vez, está relacionada diretamente com a quantidade de carbono lábil existente no solo. Entretanto, a interpretação dos valores dos indicadores biológicos deve ser feita com critério, uma vez que alta atividade microbiana nem sempre indica condições desejáveis: a curto prazo pode significar liberação de nutrientes para as plantas e, a longo prazo, perda de carbono orgânico do solo para a atmosfera (Araújo et al., 2007). Desta forma, valores elevados de RBS tanto podem indicar situações de distúrbio quanto de alto nível de produtividade do sistema (Islam \& Weil, 2000). 
Os atributos do solo que propiciaram os maiores índices de correlação com o segundo componente principal $(r>0,60)$ foram os quocientes metabólico e microbiano e o teor de cobre disponível. Referidos atributos foram responsáveis por discriminar a semeadura direta em relação ao preparo convencional do solo.

$\mathrm{O} \mathrm{CO}_{2}$ apresentou maior valor sob preparo convencional do solo (Tabela 4). Valores elevados desse atributo são indicativos de ecossistemas submetidos a alguma condição de estresse ou distúrbio (Moreira \& Siqueira, 2006). Tal preparo promove rompimento dos macro e microagregados e, consequentemente, torna a matéria orgânica mais suscetível ao ataque microbiano, o que aumenta a taxa de mineralização e liberação de $\mathrm{CO}_{2}$ para a atmosfera (Costa et al., 2004). Pereira et al. (2007) e Ferreira et al. (2010) observaram maior $\mathrm{qCO}_{2}$ no solo sob preparo convencional do que em semeadura direta. À medida em que a biomassa microbiana se torna mais eficiente na utilização de recursos do ecossistema, menos $\mathrm{CO}_{2}$ é perdido pela respiração e maior proporção de carbono é incorporada aos tecidos microbianos, resultando em diminuição do $\mathrm{qCO}_{2}$. Menores valores de $\mathrm{qCO}_{2}$ indicam agroecossistemas mais estáveis. A semeadura direta proporciona condições mais favoráveis ao desenvolvimento dos micro-organismos, relacionadas ao nãorevolvimento do solo e à cobertura morta, como menor rompimento da hifa dos fungos, proteção do habitat microbiano, aumento do conteúdo de umidade do solo e condições menos extremas de temperatura (Rhoton, 2000; Pereira et al., 2007).

O maior valor do qmic verificado na semeadura direta (Tabela 4) concorda com os resultados de Leite et al. (2010). Este quociente é influenciado por diversos fatores, como grau de estabilização do carbono orgânico e o histórico de manejo do solo. As variações em qmic refletem o padrão do aporte de matéria orgânica do solo, a eficiência da conversão do carbono microbiano, as perdas de carbono do solo e a estabilização do carbono orgânico pelas frações minerais do solo. Assim, qmic indica se o conteúdo de carbono está se mantendo estável ou variando de acordo com as condições impostas ao sistema (Tótola \& Chaer, 2002). Em ecossistemas estáveis, nos quais predominam condições favoráveis, há tendência de aumento da atividade microbiana e, em consequência, o qmic tende a crescer, até atingir um nível de equilíbrio (Insam \& Domsch, 1988).

O maior teor de cobre disponível verificado no solo preparado convencionalmente (Tabela 3 ) foi consequência do maior valor inicial desse nutriente nos experimentos sob este preparo do solo.

Os atributos do solo que propiciaram os maiores índices de correlação com o terceiro componente principal $(r>0,60)$ foram o pH, o teor de zinco disponível, a saturação por bases e o $\mathrm{qCO}_{2}$. Esses atributos foram responsáveis por discriminar os experimentos com feijão em relação aos com milho.

O maior teor de zinco disponível verificado nos experimentos com feijão (Tabela 3) foi consequência do maior valor inicial desse nutriente nos experimentos mencionados.

Os maiores valores da saturação por bases nos experimentos com milho foram devidos aos menores valores de $\mathrm{H}^{+}+\mathrm{Al}^{3+}$ (dados não apresentados), possivelmente em consequência de valores mais elevados de $\mathrm{pH}$ (Tabela 3). Teixeira et al. (2003) verificaram que a adição de restos orgânicos ao solo promoveu neutralização da acidez potencial, aumentando as cargas negativas do solo disponíveis para a adsorção de cátions básicos. A redução da acidez potencial pode ser atribuída ao efeito do $\mathrm{pH}$ nas cargas variáveis do solo.

$\mathrm{O} \mathrm{qCO}_{2}$ foi maior nos experimentos com feijão (Tabela 4), indicando menor estabilidade do sistema com aceleramento da decomposição dos resíduos. A proteção física da matéria orgânica contra a ação microbiana exercida pela estrutura do solo promovida pelas raízes fasciculadas das gramíneas, como constataram Balesdent et al. (2000), possivelmente é a causa do menor $\mathrm{qCO}_{2}$ nos experimentos com milho.

As plantas de cobertura não foram discriminadas pelos três componentes principais que explicaram a maior parte da variância total, mostrando que seu efeito nos atributos do solo foi similar.

A análise de agrupamento aplicada aos atributos do solo confirmou a separação entre os tratamentos, sendo formados três grupos com uma distância euclidiana média de aproximadamente 19 (Figura 1). Os experimentos de feijão e milho sob semeadura direta formaram um grupo (G2) e os de feijão e milho sob preparo convencional do solo formaram outro grupo (G3) e se mostraram mais próximos entre si e mais distantes da referência $(\mathrm{G} 1)$.

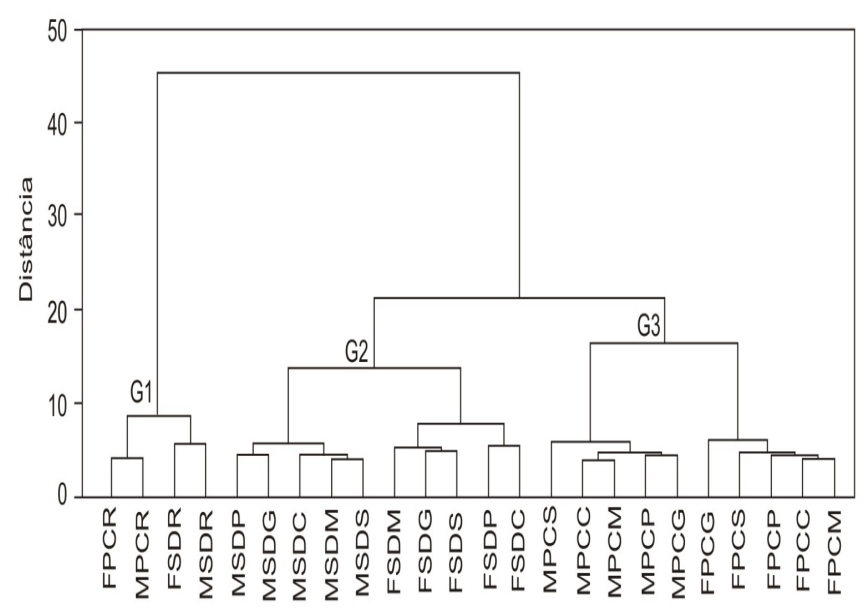

Obs.: F: feijão; M: milho; SD: semeadura direta; PC: preparo convencional; R: referência; P: pousio; $\mathrm{G}$ : guandu; C: crotalária; $\mathrm{M}$ : mucuna; $\mathrm{S}$ : sorgo

Figura 1. D endograma de agrupamento dos tratamentos construídos a partir da matriz de distâncias euclidianas médias, para a camada de 0-0,10 m

Diminuindo a distância euclidiana média para em torno de 10, observa-se que os grupos G2 e G3 formaram subgrupos, sendo que cada subgrupo separou a cultura do milho da do feijão; contudo, não se observa separação entre as plantas de cobertura do solo. Esses resultados corroboram os encontrados por Ferreira et al. (2010), que relataram um efeito claro do sistema de manejo do solo no agrupamento dos tratamentos porém sem efeito das plantas de cobertura e das rotações de culturas. No caso deste trabalho a ausência de efeito das coberturas do solo pode estar relacionada à baixa produção de massa seca das mesmas, devido à época em que foram plantadas e à rápida mineralização da matéria orgânica em função das características edafoclimáticas da região. 


\section{CONCLUSÕES}

1. Os sistemas de cultivo provocaram alterações nos atributos físicos e biológicos do solo quando comparados com os da condição preservada do ambiente de mata, e nos atributos químicos, quando comparados à condição química inicial do solo.

2. Os atributos físicos foram mais sensíveis em detectar mudanças na qualidade do solo sob cultivo.

3. O índice $\mathrm{S}$ apresentou-se como o atributo do solo com maior correlação com o primeiro componente principal, mostrando ser um indicador adequado da qualidade do solo.

4. Os quocientes metabólico e microbiano foram os atributos do solo mais afetados negativamente pelo preparo convencional quando comparados com os da semeadura direta.

5. Os atributos químicos do solo foram mais sensíveis em discriminar a cultura do feijão da do milho.

6. Os três primeiros componentes principais e a análise de agrupamento pelo método de Ward não discriminaram as plantas de cobertura com relação aos seus efeitos nos atributos do solo.

\section{LITERATURA CITADA}

Alleoni, L. R. F.; Cambri, M. A.; Caires, E. F. Atributos químicos de um Latossolo de Cerrado sob plantio direto, de acordo com doses e formas de aplicação de calcário. Revista Brasileira de Ciência do Solo, v.29, p.923-934, 2005.

Altieri, M. Agroecologia: Bases científicas para a agricultura sustentável. Guaíba: Agropecuária, 2002. 592p.

Anderson, J. P. E.; Domsch, K. H. The metabolic quotient ( $\left.\mathrm{qCO}_{2}\right)$ as a specific activity parameter to asses the effects of environmental conditions, such as $\mathrm{pH}$, on the microbial biomass of forest soils. Soil Biology \& Biochemistry, v.25, p.393-395,1993.

Andrade, R. da S.; Stone, L. F.; Silveira, P. M. da. Culturas de cobertura e qualidade física de um Latossolo em plantio direto. Revista Brasileira de Engenharia Agrícola e Ambiental, v.13, p.411-418, 2009.

Aratani, R. G.; Freddi, O. da S.; Centurion, J. F.; Andrioli, I. Qualidade física de um Latossolo Vermelho acriférrico sob diferentes sistemas de uso e manejo. Revista Brasileira de Ciência do Solo, v.33, p.677-687, 2009.

Araújo, R.; Goedert, W. J.; Lacerda, M. P. C. Qualidade de um solo sob diferentes usos e sob cerrado nativo. Revista Brasileira de Ciência do Solo, v.31, p.1099-1108, 2007.

Balesdent, J.; Chenu, C.; Balabane, M. Relationship of soil organic matter dynamics to physical protection and tillage. Soil \& Tillage Research, v.53, p.215-230, 2000.

Carneiro, M. A. C.; Souza, E. D. de; Reis, E. F. dos; Pereira, H. S.; Azevedo, W. R. de. Atributos físicos, químicos e biológicos de solo de Cerrado sob diferentes sistemas de uso e manejo. Revista Brasileira de Ciência do Solo, v.33, p.147-157, 2009.

Cavalcante. E. G. S.; Alves, M. C.; Souza, Z. M. de; Pereira, G. T. Variabilidade espacial de atributos físicos do solo sob diferentes usos e manejos. Revista Brasileira de Engenharia Agrícola e Ambiental, v.15, p.237-243, 2011.
Corrêa, J. C. Efeito de sistemas de cultivo na estabilidade de agregados de um Latossolo Vermelho-Amarelo em Querência, MT. Pesquisa Agropecuária Brasileira, v.37, p.203-209, 2002.

Correia, N. M.; Durigan, J. C. Culturas de cobertura e sua influência na fertilidade do solo sob sistema de plantio direto (SPD). Bioscience Journal, v.24, p.20-31, 2008.

Costa, F. de S.; Bayer, C.; Albuquerque, J. A.; Fontoura, S. M. V. Aumento de matéria orgânica num latossolo bruno em plantio direto. Ciência Rural, v.34, p.587-589, 2004.

Cruz, C. D.; Regazzi, A. J. Modelos biométricos aplicados ao melhoramento genético. Viçosa: UFV, 1994. 390p.

Cruz-Castilho, J. G.; Ganeshanandam, S.; Mackay, B. R.; Lawes, G. S.; Lawoko, C. R. O. O.; Woolley, D. J. Applications of canonical discriminant analysis in horticultural research. HortScience, v.29, p.1115-1119, 1994.

Dexter, A. R. Soil physical quality. Part 1 . Theory, effects of soil texture, density, and organic matter, and effects on root growth. Geoderma, v.120, p.201-214, 2004.

EMBRAPA - Empresa Brasileira de Pesquisa Agropecuária. Centro Nacional de Pesquisa de Solos. Manual de métodos de análise de solos. 2.ed. Rio de Janeiro: Embrapa CNPS, 1997. 212p. Documentos, 1.

Ferreira, E. P. B.; Santos, H. P.; Costa, J. R.; De-Polli, H.; Rumjanek, N. G. Microbial soil quality indicators under different crop rotations and tillage managements. Revista Ciência Agronômica, v.41, p.177-183, 2010.

Fialho, J. S.; Gomes, V. F. F.; Oliveira, T. S. de; Silva Júnior, J. M. T. Indicadores da qualidade do solo em áreas sob vegetação natural e cultivo de bananeiras na Chapada do Apodi-CE. Revista Ciência Agronômica, v.37, p.250-257, 2006.

Insam, H.; Domsch, K. H. Relationship between soil organic carbon and microbial biomass on chronosequences of reclamation sites. Microbial Ecology, v.15, p.177-188, 1988.

Islam, K. R.; Weil, R. R. Land use effects on soil quality in a tropical forest ecosystem of Bangladesh. Agriculture, Ecosystems \& Environment, v.79, p.9-16, 2000.

Jakelaitis, A.; Silva, A. A. da; Santos, J. B. dos; Vivian, R. Qualidade da camada superficial de solo sob mata, pastagens e áreas cultivadas. Pesquisa Agropecuária Tropical, v.38, p.118-127, 2008.

Jenkinson, D. S.; Powlson, D. S. The effects of biocidal treatments on metabolism in soil. A method for measuring soil biomass. Soil Biology \& Biochemistry, v.8, p.209-213, 1976.

Leite, L. F. C.; Galvão, S. R. S.; Holanda Neto, M. R.; Araújo, F. S.; Iwata, B. F. Atributos químicos e estoques de carbono em Latossolo sob plantio direto no cerrado do Piauí. Revista Brasileira de Engenharia Agrícola e Ambiental, v.14, p.12731280, 2010.

Moreira, F. M. S.; Siqueira, J. O. Microbiologia e bioquímica do solo. 2.ed. Lavras: UFLA, 2006. 729p.

Nunes, L. A. P. L.; Araújo Filho, J. A. de; Holanda Júnior, E. V; Menezes, R. I. de Q. Impacto da queimada e de enleiramento de resíduos orgânicos em atributos biológicos de solo sob caatinga no semi-árido nordestino. Revista Caatinga, v.22, p.131-140, 2009. 
Pereira, A. A.; Hungria, M.; Franchini, J. C.; Kaschuk, G.; Chueire, L. M. de O.; Campo, R. J.; Torres, E. Variações qualitativas e quantitativas na microbiota do solo e na fixação biológica do nitrogênio sob diferentes manejos com soja. Revista Brasileira de Ciência do Solo, v.31, p.1397-1412, 2007.

Pereira, S. A.; Oliveira, G. C. de; Severiano, E. da C.; Balbino, L. C; Oliveira, J. P. de. Análise de componentes principais dos atributos físicos de um Latossolo Vermelho distrófico típico sob pastagem e mata. Global Science and Technology, v.3, p.87-97, 2010.

Pôrto, M. L.; Alves, J. do C.; Diniz, A. A.; Souza, A. P. de; Santos, D. Indicadores biológicos de qualidade do solo em diferentes sistemas de uso no Brejo Paraibano. Ciência e Agrotecnologia, v.33, p.1011-1017, 2009.

R Development Core Team. R: A language and environment for statistical computing. Vienna: R foundation for statistical computing, 2011. http://www.R-project.org. 25 Jan. 2011.

Rhoton, F. E. Influence of time on soil response to no-tillage practices. Soil Science Society of America Journal, v.64, p.700-709, 2000.

Silva, A. P.; Babujia, L. C.; Franchini, J. C.; Souza, R. A.; Hungria, M. Microbial biomass under various soil- and cropmanagement systems in short- and long-term experiments in Brazil. Field Crops Research, v.119, p.20-26, 2010.

Silva, F. de F. da; Freddi, O. da S.; Centurion, J. F.; Aratani, R. G.; Andrioli, F. F.; Andrioli, I. Propriedades físicas de um Latossolo Vermelho cultivado no sistema plantio direto. Irriga, v.13, p.191-204, 2008.
Silva, S. C.; Xavier, L. de S.; Santana, N. M. P. de; Cardoso, G. M.; Pelegrini, J. C. Informações meteorológicas para pesquisa e planejamento agrícola referentes ao município de Santo Antônio de Goiás, GO, 2001. Santo Antônio de Goiás: Embrapa Arroz e Feijão, 2002. 21p. Documentos, 136.

SSSA - Soil Science Society of America. Statement on soil quality. Madison: Agronomy News, 1995. 200p.

Stolf, R.; Fernandes, J.; Furlani Neto, V. L. Penetrômetro de impacto, IAA/Planalsucar-Stolf: recomendações para o seu uso. STAB, v.1, p.18-23, 1983.

Teixeira, I. R.; Souza, C. M. de; Borém, A.; Silva, G F. da. Variação dos valores de $\mathrm{pH}$ e dos teores de carbono orgânico, cobre, manganês, zinco e ferro em profundidade em Argissolo Vermelho-Amarelo, sob diferentes sistemas de preparo do solo. Bragantia, v.62, p.119-126, 2003.

Tótola, M. R.; Chaer, G. M. Microorganismos e processos microbiológicos como indicadores de qualidade dos solos. In: Alvares, V. H.; Schaefer, C. E. G. R.; Barros, N. F.; Mello, J. W. V.; Costa, L. M. (ed.). Tópicos em ciência do solo. Viçosa: Sociedade Brasileira de Ciência do Solo, v.2, p.195276, 2002.

Vance, E. D.; Brookes, P. C.; Jenkinson, D. S. An extraction method for measuring soil microbial biomass C. Soil Biology \& Biochemistry, v.19, p.703-707, 1987.

Vezzani, F. M.; Mielniczuk, J. Uma visão sobre qualidade do solo. Revista Brasileira de Ciência do Solo, v.33, p.743-755, 2009. 